\title{
Vocabulary Theatre: A Peer-teaching Approach for Academic Vocabulary Acquisition
}

\author{
Elizabeth Robb ${ }^{1}$, Richard Sinatra ${ }^{2} \&$ Robert Eschenauer ${ }^{3}$ \\ ${ }^{1}$ The School of Education, St. John's University, 8000 Utopia Parkway, Jamaica, NY 11439, USA \\ ${ }^{2}$ Professor of Literacy and Associate Dean of Academic Affairs, The School of Education, St. John's University, \\ 8000 Utopia Parkway, Jamaica, NY 11439, USA \\ ${ }^{3}$ Associate Professor and Director of Counselor Education Programs, The School of Education, St. John's \\ University, 8000 Utopia Parkway, Jamaica, NY 11439, USA \\ Correspondence: Elizabeth Robb, Adjunct Professor, The School of Education, St. John's University, 8000 \\ Utopia Parkway, Jamaica, NY 11439, USA.
}

Received: August 2, 2013 Accepted: August 16, 2013 Online Published: October 21, 2013

doi:10.11114/jets.v2i1.247 URL: http://dx.doi.org/10.11114/jets.v2i1.247

\begin{abstract}
This mixed methods counterbalanced study compared the gain score means of two different approaches to vocabulary acquisition - Vocabulary Theater (VT) and Teacher Directed Instruction (TDI) for $8^{\text {th }}$ grade students from three schools in New York. The purpose of the study was to explore the effects of a peer teaching approach on students' vocabulary development. Students in the VT condition were instructed to take ownership of their words by teaching them to their peers. They received both linguistic and non-linguistic representations of 30 Scholastic Aptitude Test (SAT) words over a three-week period, while the TDI condition students were instructed over the same three-week period to define the same 30 SAT words through the use of a dictionary and then use the words in sentences. The study's counterbalanced design ensured that all students received each vocabulary condition. Students were given a pre- and posttest to examine their level of vocabulary acquisition in each condition. A survey given to the students in the VT condition revealed that on average $43 \%$ of the students were totally unfamiliar with the words presented, $14 \%$ had an associative connection with the words presented and $13 \%$ were very familiar with the words. Qualitative data were collected from all three schools in the form of group discussions, VT presentations, individual interviews, teacher interviews, and classroom observations. The quantitative analysis revealed that the gain scores of students in the Vocabulary Theatre were significantly greater than the gain scores of students in the TDI condition regardless of the presentation order.
\end{abstract}

Keywords: Vocabulary Theatre, academic vocabulary, adolescents, peer teaching, dictionary use, grouping, SAT words

\section{Introduction}

\subsection{Introduce the Problem}

With so many words that students need to learn today, and the fact that these words cannot be learned incidentally, direct vocabulary instruction aids students in enriching their thinking, their ability to communicate effectively, and their reading comprehension. The dilemma teachers face is how to incorporate a typical 40-minute period with effective classroom practice that includes effective vocabulary instruction. Additionally, struggling readers need to learn a corpus of academic words to be successful in all subjects in school (Blachowicz \& Fisher, 2004).

Adolescents' informal language is often quite different from the formal vocabulary they encounter daily in their classrooms. Frequently, the academic language they hear in a classroom and the social language they are engaged with outside of school are incongruous. A national report (NICHD, 2000) and many educators have noted that vocabulary development is crucial to gain full understanding of texts particularly in the middle school years and beyond (Blachowicz \& Fisher, 2000; Lesaux, Kieffer, Faller, \& Kelly, 2010; Townsend, 2009). Furthermore, adolescents need to understand and use the words most frequently used in college entrance exams 
like the Scholastic Aptitude Test (SAT) in order to compete competitively with their peers and to reveal that they know sophisticated language (Terrill, Scruggs, Mastropieri, 2004).

Teachers can capitalize on adolescents' energy, social networking, and zeal for learning in nontraditional ways by allowing them to be the primary teacher of their peers in the learning of new, sophisticated vocabulary. This paper presents an experimental study whereby eighth graders participated in two vocabulary development conditions: one in which they took responsibility for the teaching of academic vocabulary to each other through a theatrical approach, and the other where they were given a list of 10 weekly words to learn through traditional dictionary exposure and print follow up. In the former condition, the teacher trained students in the steps of the approach and then structured the classroom environment to let the students take over while in the latter the teacher directed students to work individually to learn the week's words.

\subsection{Explore Importance of the Problem}

A wake-up call may have reverberated through the educational community after the National Reading Panel published its findings on the relationship between vocabulary knowledge and oral and print comprehension (NICHD, 2000). Fifty experimental and/or quasi-experimental studies reviewed from 1979 to 2000 revealed findings that repetition, multiple exposure, and active engagement by students were important procedures for successful vocabulary instruction to improve comprehension. This renewed focus was a far cry from the earlier labeling of vocabulary research as a "vanishing species" (Calfee \& Drum, 1978). Students need to read to excel in school, and reading involves knowing words. Research indicates that vocabulary understanding is a major component to enhance and deepen reading comprehension (NICHD, 2000; Nagy \& Scott, 2004; Blachowicz \& Fisher, 2004). Students must have many opportunities to use their new vocabulary (Beck \& McKeown, 1991; Gunning, 2006; Nagy \& Scott, 2004) so that they can reveal word ownership through expressive, productive language.

\subsection{Relevant Scholarship}

In 2002, Beck, McKeown, and Kucan categorized words into three levels of "tiers" to account for the diversity and frequency of word usage in the English language. Tier one words are described as those most frequently used in the oral and print language systems; tier two words occur in more mature speech and reading materials and can be found and used across content topics, such as divide, conquer, industrious, and diverse; and tier three words are generally associated with the learning of discipline-specific topics and students encountered them as a specific topic was taught. While students might face new words when learning a discipline-specific topic such as photosynthesis, some of the words such as reaction, transport, absorb, decompose, and nutrient will conceivably appear during other learning situations and in other textual readings. Although learned in a tier three context, such words become more meaningful to learn as they assist understanding in other contexts.

In 2010, one of the six shifts in the Common Core Learning Standards was specifically designated as "Academic Vocabulary" (National Governors Association Center for Best Practices, Council of Chief State School Offices). Possibly a strategic collapse of the tier two and three categorizations (Beck, McKeown, \& Kucan, 2002), academic vocabulary (as defined by the Common Core) are the words which students constantly learn and cumulatively add to their existing vocabularies as they encounter more complex texts used during differing academic disciplines. Nagy and Townsend (2012) added that academic vocabulary is most often used during content instruction and needed for the learning of discipline specific topics.

The National Assessment of Educational Progress (NAEP) reanalyzed data from the "Nation's Report Card" to examine $4^{\text {th }}$ and $8^{\text {th }}$ graders understanding of vocabulary (National Center for Education Statistics, 2011). The NAEP measured students' vocabulary knowledge by examining their understanding of word meanings as they were used in the reading comprehension passages. Students who did well on the vocabulary questions also performed well with reading comprehension. Conversely, students who scored at or below the $25^{\text {th }}$ percentile in reading comprehension also scored quite poorly on the vocabulary items with students eligible for subsidized lunch scoring lower than non subsidized students. Based on a $0-500$ scoring scale, the $4^{\text {th }}$ grade gap between subsidized and non subsidized students was 31 points and at the $8^{\text {th }}$ grade level, the gap was 28 points.

Since the 2000 National Reading Panel report, educators and researchers have continued to stress the importance of vocabulary development. Acquisition of vocabulary enhances thinking and communication (Adams, 2009), improves the ability to gain meaning from text (Baumann, Kame'enui, \& Ash, 2003; Biemiller, 2003; Lesaux, Kieffer, Faller, \& Kelley, 2010), becomes a key ingredient in overall academic achievement (Blachowicz, Fisher, Ogle, \& Watts-Taffe, 2006), and is needed to maximize success on the SATs and other standardized tests (Hardwick-Ivey, 2008; Terrill, Scruggs, \& Mastropieri, 2004). Moreover, the practice of curtailing more sophisticated vocabulary in the early reading materials of less capable students may have served to further 
disadvantage them from the word wealth they would have needed as they faced more advanced reading materials and information in later grades (Adams, 2009).

\subsection{Hypotheses}

The central quantitative research question posted was if students would attain a higher posttest retention score through a condition entitled Vocabulary Theatre compared to those students who were taught through the traditional vocabulary method of learning by receiving lists of words and learning their definitions from dictionary usage. Also, students in the study completed a survey to examine their knowledge of a word and to also examine the cognitive processes they exhibited when they encountered a vocabulary word through print.

\section{Method}

The purpose of the present study was to explore the effects of a peer teaching approach on eighth grade students' vocabulary development. The approach grew out of the first author's experience in teaching young adolescents as an English Language Arts (ELA) and SAT preparation teacher over a 14-year period. She noted that successful performance on the Critical Reading Section of the SATs was highly influenced by vocabulary knowledge and that many of the words students faced on standardized tests were not words they would hear and use in everyday conversation nor see and use in their academic classes. She developed a technique, which became known as "Vocabulary Theatre," whereby they would act out word meanings in short vignettes and use posters as props that displayed word images as well as the words. She now wished to test the effects of the theatre approach by comparing it with a more traditional way in which vocabulary development occurs in school settings. Students assigned to the Vocabulary Theatre (VT) condition were instructed by their teachers to take ownership of the verbal and nonverbal ways they would teach the week's new words to their peers. Students assigned to the Teacher Directed Instruction (TDI) condition were instructed to find the definitions of the week's words through dictionary use, write out the definitions, and then use the words in sentences. A counter-balanced design was followed to allow for all students to participate in both conditions in this quasi-experimental study. To ensure the fidelity of the two instructional approaches, both students and teachers were aware of what condition they were in during each 3 -week period.

\subsection{Participants}

A convenience sample of 121 eighth grade students ranging in age from 12 to 13 from three schools located in urban, suburban, and rural settings participated in the two conditions. Students were 57\% female, $43 \%$ male, $89 \%$ White, and $11 \%$ identified as Latino/Hispanic, Black/African American, Asian, and mixed ethnicity. The teaching experience of the three English Language Arts (ELA), White, female teachers was 31, 17, and 5 years, and each had a Master's degree and an appropriate teaching license.

\subsection{Measures}

Three types of instruments were used to assess the effectiveness of the study procedures. Identical pre and post vocabulary tests were prepared for 30 words used in both conditions during two phases of three-week cycles; a survey was prepared to measure a student's level of a word's familiarity; and interview questions were prepared for students and teachers.

\subsubsection{Vocabulary Knowledge Tests}

The 60 words chosen for use in this study were found in SAT published sources: Barron's SAT Prep (Green \& Wolf, 2010), Hot Words for the SAT (Carnevale, 2010), Vocabulary Power Plus for the New SAT, Books 1, 2, 3, and 4 (Reed, 2004), and the Sadlier Vocabulary Levels C, D, E, and F (Shostak, 2005). Words had to appear on at least three of the four sources while most were listed on all four. Furthermore each word was located in Word Count (http://www.wordcount.org/main.php) to determine its frequency of occurrence in the English language based on a corpus of 86,800 words. For instance, appease had a frequency count of 25,826 , duplicity a count of 31,691 , garrulous a count of 45,089, and extol, a count of 51,886. Two vocabulary tests consisting of 30 words each were used to measure students' learning efficiency of 10 words introduced each week of each three-week condition. The pre and post vocabulary tests were constructed using the Stanford Diagnostic Reading Test, Vocabulary battery as a model (Karlsen \& Gardner, 1996). St. John's University professors and doctoral students in the literacy program examined and provided feedback regarding the definitions used and the wording of the three incorrect choices to insure that students had the opportunity to select the best choice. All 60 words were a balanced mix of nouns, verbs, or adjectives. Once the 60 words were divided between Phase I and Phase II introduction, based on frequency counts, an assistant randomly sorted the words to compile sets of six weekly words as the study required the use of 10 words per week for both conditions. 


\subsubsection{Survey}

When students participated in the VT condition, they were solely responsible for researching and teaching one word for each of the three weeks. The lead researcher wished to examine students' mental process as they saw a new word for possibly the first time as often occurs to students when confronted with receptive vocabulary understanding on standardized tests. The study teachers were instructed to present one different word from the list of ten silently to each student by highlighting that one word from the 10 word weekly list handout that was distributed to each student. The one word highlighted determined that student's "One Word" for that week. After seeing the word, the student wrote it on top of the survey handout and then was instructed to check off any number of the eight statements that applied to his/her familiarity of that word. Two of the statements, had to do with no or little knowledge of the word, i.e., "I never saw this word before. I have seen it before, but I don't know what it means." Three of the statements had to do with associative connections to the word's meaning; i.e., "I think of a picture when I see this word. I think of a sound... I think of another word..." Three of the statements had to do with knowledge of the word; i.e., "I know the word well. I can use this word in a spoken sentence. I can use this word in a written sentence."

\subsubsection{Interview Questions}

Nine questions were used by the lead researcher during whole-class and individual interviews with students from the three schools. Questions focused on levels of engagement, the process of looking up words through dictionary use, the process of the Vocabulary Theatre approach and using nonverbal representations to learn words, the ways that word ownership occurred, and how it felt to be the teacher of their peers.

\subsection{Instructional Materials}

\subsubsection{Teacher Directed Instruction (TDI) Materials}

The TDI materials consisted of pocket or personal dictionaries, a list of the 10 words to research for each of the three weeks and traditional writing materials whereby students could write definitions and original sentences using the words. The TDI approach did not allow for students to have access to any computer keyboard use during ELA class time since in-class computers were not available at any of the three schools during the study.

\subsubsection{Vocabulary Theatre (VT) Materials}

The VT materials consisted of the students' Word Power handout and a mini-poster handout while the teachers were given instructions for the cooperative groups. The Word Power handout gave students a list whereby they could research and provide information about that word: its definition, other forms of the word, part of speech, sentence from the dictionary, synonyms, antonyms (when applicable), original sentence, associational picture / image of word, and the etymology of the word.

The mini-poster instructions called for students to make a poster of their week's One Word by showing the printed form of the word, a picture or drawing which represented the meaning of the word, the word's definition, and an original sentence connected to the meaning represented in the illustration. Since the classes were composed of more than ten students and the number of weekly vocabulary words was ten, there was an overlap of the distribution of the words among the students; therefore, teachers were instructed to make sure that each cooperative group did not contain students who had the same One Word assignment.

\subsection{Procedure}

\subsubsection{Teacher Training}

After meeting with each of the school's principals for permission to conduct the study, the lead researcher trained the ELA teachers at their respective school sites over three sessions. First, they were apprised of the study's purpose, rationale, and general methodology of the two conditions. Second, they were trained in the VT instructional approach and how they would conduct the TDI condition during each weekly time frame. In the final session, they examined lesson plans prepared by the researcher for a pilot study, watched videos of adolescents engaged in the VT approach, and were shown artifacts from former pilot study participants. Teachers agreed they would follow the protocol for each condition of the study, particularly during the One Word presentation to each individual student.

\subsubsection{Instructional Procedure}

The two instructional procedures, TDI and VT, occurred over three-week periods at each school to account for the 60 words introduced during the study. During the TDI condition, the 10 target words were taught over a three-day weekly session, usually Monday, Wednesday, and Friday during a 40 minute period. The same 30 words covered during this TDI condition were presented to students in the VT condition. During the TDI periods, 
students alone or in pairs investigated the meaning of the week's 10 words through dictionary use and used the words in written sentences. Teachers assisted students with word pronunciation, definition meanings, and sentence writing. The time devoted to TDI and VT was consistent at all three schools.

During the first 40-minute period of the VT condition, the teacher distributed the 10 word weekly list (as per the TDI condition) but each student had only one of the 10 words highlighted. The teacher had planned ahead with the format of the cooperative groups, generally three to four students, so that all of the week's 10 words would be strategically distributed among the groups. After each student wrote their One Word on their survey and checked off responses to the eight questions, the teacher collected the surveys and then started to review the pronunciation and meaning of each word with the whole class. Teachers were prompted to pronounce the words in a choral manner allowing reluctant students to be more at ease when pronouncing the new words. For homework, teachers then directed students to research and provide the information on the Word Power handout so that they could comfortably teach the word to their peers during the next class session.

At the second 40-minute session, students initially presented their One Word information to members of their cooperative groups. The ELA teacher moved from group to group, listened to the preliminary presentations, corrected misconceptions if they occurred, explained and teased out nuances of the word, and then offered advice as to how the words might be connected. Students now began to interact with one another by considering ways the group's words could be used in a theatrical skit. Students could use verbal or nonverbal means, such as music, art, or body movement to enhance the meaning generated through their words. Many groups used a storyboard organizer to map out different scenes of their skits. So that students viewing the skit had the opportunity to learn the words not assigned to their group, skit presenters were asked in the group instructions to do three things to help their peers' comprehension. First, as a word was used orally during the skit, one group member would hold up a poster with the printed word. Second, a presenter had to present the meaning and a context clue in his or her skit to assist the peer audience with a word's understanding. For example, for the word prosaic, the presenter said "This is so prosaic: this is so boring; this is so dull!" Third, the mini-poster needed to be displayed or held up by each member of the group at the end of the skit. The mini-poster contained a variety of verbal and nonverbal clues to a word's meaning. For instance, the picture clue to the meaning of meticulous showed a man on his hands and knees with scissors trimming the tops of blades of grass. The sentence on the mini-poster read, "The man was so meticulous as he trimmed his lawn so every strand of grass was perfectly one-inch high." Session two ended with students assigning skit roles and tasks and with plans to meet as a group to practice before the full class presentation.

Session three mainly consisted of the students' lively theatrical performances using their group words. After each three to five minute skit, each group member would hold the mini poster, explain the word's meaning, point out how the illustration supported the word's meaning, and read the original sentence. When the lead researcher observed this portion of the study in all three schools, each classroom was alive with students' creative chatter as they discussed word meanings and how they could be applied in a skit. One of the teachers even said "We had to close the door once in a while because the students really got into it!" Another teacher remarked on the high energy of students who were interpreting their own meanings of the words while practicing their skits. A student explained this process as well when she said "We thought of it in a way that you are the word that you are acting out. And you are representing the word that every other word that you are watching can understand- it's a weird process- but you just understand the word because you are seeing not how it is used in a sentence but how that word is used in life. You're seeing beyond the sentences that you are acting out. We learn English vocabulary through interaction."

\subsubsection{Research Design}

The six-week counterbalanced design required that each school conduct two phases consisting of three weeks each. The identical procedure for administering the pre and posttests was followed for each condition and phase. During each three-week phase, students in both the VT and the TDI conditions were pretested on the 30-word vocabulary the day before the phase commenced and were posttested one day after the phase was completed. When students were in the VT condition, they acknowledged via the survey their familiarity/understanding of the three words (one word per three weeks) that would become their words to teach during the VT condition. For all students in the VT condition the statements on the survey were later tallied to reveal familiarity with the words assigned. After both conditions and phases were completed at each school, the lead researcher conducted a whole-class interview as the classroom teacher videotaped the session. Then teachers at each school randomly selected four to five students who participated in an individual interview with the lead researcher in a separate classroom setting. Finally, each teacher was interviewed during a break period or after school. 


\section{Results}

This study used quantitative and qualitative measures to examine the effectiveness of the instructional procedures.

\subsection{Quantitative Results}

\subsubsection{ANOVA Results}

The central quantitative research question asked whether vocabulary performance would be significantly stronger as a result of the VT condition when compared to the TDI condition. To address this question a crossover within-group design was used to compare groups; therefore, all students received vocabulary instruction through both the VT and TDI approaches. A $2 \times 2$ split plot analysis of variance (ANOVA) was performed with two independent variables.

The between-subject independent variable, Phase, consisted of two levels. In the first level students were exposed to the Vocabulary Theatre first and then to the Teacher Directed Instruction. In the second level the order of presentation was counterbalanced. Students were exposed to the TDI first and then to the VT. The within-subject independent variable (Condition) consisted of the pre- and posttest scores of the subjects in each of the above conditions. The dependent variable was the gain score determined by subtracting the pretest score from the posttest score for each subject. The descriptive statistics for each condition are contained in Table 1 . It should be noted that within the Vocabulary Theatre first condition, the gain scores of the TDI group ranged from -5 to +17 with 14 of the students making no gain or actually scoring below their pretest score. This wide variability is reflected in the standard deviation of 5.32 .

Table 1. Descriptive Statistics of Gains

\begin{tabular}{ll}
\hline Phase: Vocabulary Theatre First & Phase: Vocabulary Theatre Second \\
\hline VT Gains $\quad(M=12.04, S D=4.65)$ & TDI Gains $(M=9.31, S D=5.10)$ \\
TDI Gains $(M=4.21, S D=5.32)$ & VT Gains $\quad(M=11.50, S D=5.14)$ \\
\hline
\end{tabular}

A two-way split-plot analysis of variance was computed on the gain scores using an adjusted Bonferroni alpha level of .017 to test significance and maintain a study-wise Type 1 error at .05 . The within-subject main effect of Condition was found to be statistically significant, $F(1,94)=69.7, p<.001, \eta^{2}=.426$. The between-subject main effect of Phase was also found to be statistically significant, $F(1,94)=6.768, p=.011, \eta^{2}=.067$. The interaction of Phase $\mathrm{x}$ Condition was significant, $F(1,94)=22.16, p<.001, \eta^{2}=.191$.

Tests of simple effects revealed that the gains of the vocabulary theatre were significantly greater than the gains of the teacher directed instruction $(p<.01)$ regardless of whether the vocabulary theatre was presented first or second. However there was no significant difference between the gain scores of vocabulary theatre groups regardless of the Condition. There was a significant difference between the gain scores of the teacher directed instruction groups $(p<.001)$ such that students who received the vocabulary theatre second scored significantly higher than those who received vocabulary theatre first.

\subsubsection{Survey Results}

A tally of the eight statements on the One Word survey completed by all participants produced the second quantitative measure. (Percentages from the survey do not add up to $100 \%$ because the students could check more than one statement from the survey.) Students in Vocabulary Theatre First received the survey at the start of Weeks 1 (survey 1), 2 (survey 2), and 3 (survey 3). Students in Vocabulary Theatre Second received the survey at the start of Weeks 4 (Survey 1), 5 (Survey 2), and 6 (Survey 3). The results for students who knew the word well was $9.3 \%$ for Survey 1; $11.7 \%$ for Survey 2; and 18\% for Survey 3. In contrast, the percentage of students who never saw the word before was $47 \%$ for Survey 1; $43 \%$ for Survey 2; and $46 \%$ for Survey 3 . Additionally, students who could use the word in a written sentence were $10 \%$ from Survey $1 ; 12 \%$ from Survey 2; and 18\% from Survey 3. The percentage of students who made a connection by associating the word with a picture or a sound was $14 \%$.

\subsubsection{Qualitative Data}

Qualitative data were collected by three levels of interviews. The first level consisted of whole class interviews conducted by the lead researcher in the language arts classroom at each of the three schools; the second, consisted of individual interviews conducted with randomly selected students, and the third, was held with each of the three study teachers. Classroom observations occurred during all phases of the study to ensure that teachers were following condition protocols, and that students produced many artifacts during both study 
conditions. Artifacts examined included VT skit group interviews, mini-posters, and power assignments. The researcher used the grounded theory method (Corbin and Stauss, 2008) of qualitative analysis which is the "process of examining and interpreting data in order to elicit meaning, gain understanding, and develop empirical knowledge" (p.1). The researcher first collected the data, and then coded the data to create categories that ultimately determined the basis for the findings of this study.

The following skit group interview demonstrates how students were highly engaged when planning how to use their assigned group words - predator, expedient, tantamount, and hyperbole - for their vocabulary skit.

Researcher: From the moment you got your words, to the moment you did the skit, tell me what happened. What was the process?

Student: I think we all really came up with ideas. We had the idea of doing the nature channel. I had the idea of doing "Bro White and the Two Dwarves."

Student: I thought about Lion King because of the word predator.

Researcher: What made you think of that connection- for predator

Student: Because of the hyenas, and because we were already doing a Disney movie so it made me think of other movies that it related to.

Researcher: So how did you think to include the word hyperbole in your skit? How did that come about?

Student: So after we decided that I would be the evil witch, I said I would say, "I told you dwarves a million times..."- and well, that's hyperbole!

Researcher: So what's your skit? Could someone explain it to me?

Student: It's "Bro White and the Two Dwarves", like a spinoff of Snow White since he's the only guy in our group. So he's Bro White, she's Smarty, she's Shorty, and I'm gonna be the Evil Queen.

Researcher: So how does your skit explain your words?

Student: Well Katie says, "She's tantamount to a predator," like equal to a predator. Then she says, "That's hyperbole" when the queen says "a million times." And Jason says, "The only expedient thing to do is run," like the only practical thing to do. And then there's a lot of fluff in between.

\section{Discussion}

The current study presented Vocabulary Theatre (VT) as a way to engage students in a peer teaching approach that offered them many opportunities to participate in their own personalization of how sophisticated words could be portrayed. First, students learned individual vocabulary words on their own, then they gleaned a deeper understanding of more vocabulary words through participation in collaborative groups as they wrote scripts and performed vocabulary vignettes, and finally they learned all ten words as receptive learners who observed and listened to their peers' skits.

Students today must understand vocabulary on so many different levels in order to succeed in school and in the workforce. They must know the abundant academic vocabulary that they are exposed to in their content area classrooms and on high-stakes tests. They need to understand this vocabulary through oral, print, receptive, or productive occurrences (Kamil \& Hierber, 2005). Also, students should be exposed to vocabulary instruction (Blachowicz \& Fisher, 2000) that consists of active learning, personalization of word learning, immersion of word knowledge, and repeated exposures to the word.

Results indicated that there was a significant difference between the gains score of students who had VT first compared to students who had TDI condition first. These results suggest that the VT condition, which used nonlinguistic and linguistic forms of the word, helped students remember their words more efficiently than when students are directed by their teacher to learn the words through linguistic means only. Results also revealed that where was a significant difference between the gains score of students who had VT second compared to students who had TDI first. This finding was corroborated by interview data that showed many students had difficulty returning to the traditional method of learning new vocabulary words after their exposure to the VT method. The effect size was greater for students who received VT first because the qualitative data from one teacher and some students suggests that students were agitated that they could not learn the new vocabulary words using skits and images, so they were reluctant that they had to resort to the traditional way of looking up meanings of words in the dictionary. Interestingly, students did make gains during the TDI condition during both phases. While not as dramatic as the VT gains, the gains occurred because students did have a dedicated 
vocabulary intervention approach three times per week. During ELA weekly class time, 120 minutes may not have been normally devoted to vocabulary instruction.

According to Gunning (2006) vocabulary knowledge is developed on three major levels. The first level is associative whereas a student learns the meaning of the word in only one particular context such as through dictionary use. The second is the comprehensive level whereas a student understands the word and that word can be expanded upon because the student learns synonyms, antonyms, classification, analogies, and connotative dictionary meanings. The third level is the generative level where students can use any variation of the word meaning independently in their speaking and writing; therefore, they can understand the word used in any context. The VT strategy commenced with the associative level and then rapidly shifted to the comprehensive level when the students became the mini researchers bringing their word knowledge information to their cooperative group members. The highest generative level (and most desired for complete word knowledge) occurred through creating or watching the skits. Marzano and Pickering (2005) noted that when students construct an image such as a picture, symbol, or graphic display to represent a word, they think of the word's meaning from a different perspective. Having such repeated exposures to words is a major principle of good vocabulary instruction (Blachowicz \& Fisher, 2000). One student reported her perspective "I like the drawing of the picture - because it made it easier to understand (the word). I remember drawing little Puss N Boots and his big eyes, like cajoling him into doing something - I thought that was fun because you got to, like, use images to describe a word instead of using a definition which can be confusing."

Students reported that when they would explain their one word to their group, the richness of this peer interaction and peer feedback helped create a deeper understanding of the vocabulary word. Because students were engaged in dialogue and the skit interaction, they constructed and shared their word knowledge. One student talked about sharing her experience of learning new words in the cooperative groups when she stated, "Also, even though you only had one word since you had to do a skit, you would memorize all the other three or four words at your table. Cause you would have to memorize the skit - not memorizing one word - you would have to memorize four words - which was easy - cause you had to do a skit which was helpful."

This method emphasized exploration, hands-on experience, inquiry, peer teaching, and collaboration among students and this occurred when students would talk about their one word assignment with each other in the beginning phases of sketching out their skit. Associative meanings of their words took on deeper generative meanings because the students tapped into their own schema to understand the nuances and connotations of the words. Because students only had to research one word, they reported that they were more highly engaged in digging deeply into the nuances and numerous meanings of the word.

Students from all three schools shared keen perspectives on what it was like to be responsible for their teaching. Dale shared the following, "I actually get to see what the teacher sees an entire classroom of kids or teens just looking at you - it's kinda intimidating at first - cause if you don't do something exciting they'll like veer off to the side which I understand is pretty annoying to some teachers - I actually get that now. But for the most part, I felt like I was helping others understand those words well." Liam expressed the following about being the teacher of his peers. "The teacher was not explaining anything to us about the definition of the word - we were even the teacher could be learning something new about the word that they might not have known before. And that is why I felt more of a teacher because the teacher was watching what you were doing and everyone had their full attention to you." Olivia stated that "you were the one that was showing them how you interpreted it and maybe they interpreted it different. But you were telling them and not being told - so you still learned but every teacher sort of learns." One of the teachers also reported she "actually enjoyed watching the kids peer teach. I saw certain kids step up and get involved that usually sat back."

There were potential biases and limitations in this study. One bias was the focus on words found in SAT published sources. While the researchers made an effort to present sophisticated, academic vocabulary to investigate how the youth would perform during the two vocabulary conditions, students may not have been challenged to learn the words at the generative level (Gunning, 2006) during the TDI dictionary condition. Some of the words may have appeared to be too abstract and out of their range of usage resulting in a curtailing of energy and creativity displayed during the VT condition.

Limitations were evident with the sample population and with the survey instrument. Most of the study's eighth grade New York participants were white with only a small percentage of minority students. Therefore, the study procedure should be replicated with diverse and ethnic minority students across a wider geographic area. However, young adolescents at the 12 and 13-year age level in the English speaking culture appear to share many of the same behavioral characteristics as portrayed in mass media. Additionally, the survey instrument 
offered too many choices for students to select. The more important statements asked whether students knew the assigned word or not. An effort was made in the study, however, to ascertain if a picture, sound, or other word association could be made with the target word. The type of statement may have been too confusing or abstract for students, leading to an unclear indication of how students reacted when the printed word was shown to them by the teacher.

Finally, the study outcomes were affected by the fidelity of the three teachers to execute the two study conditions as outlined by the lead researcher. Even though the researcher gave explicit directions to teachers in the study, it is unknown if all three adhered to the same implementation of procedures across both phases. Different implementation may have affected the results. Yet, students acknowledged during interviews that classroom teachers did follow the study procedures. Moreover the novelty of the VT approach may have suited the learning and social needs of young adolescents by allowing them to engage in peer interaction and encourage them to learn academic vocabulary. Such an approach may serve to increase motivation, allowing young adolescents to master new words with a higher rate of success.

Students experience academic words in every classroom during their school day. When they are allowed to participate in groups, instruct one another, and use their imaginations, their learning takes on a creative aspect as they construct their own contexts for learning. The many scaffolded layers of learning that occurred during the VT condition enhanced the students' acquisition of new vocabulary. VT can be a fundamental strategy to assist adolescents in learning new vocabulary as they use their natural energy to work collaboratively and meaningfully as both teachers and students. Elements of the VT condition can be implemented by other practitioners to complement their curriculum offerings and classroom settings.

\section{References}

Adams, M. J. (2009). The challenge of advanced texts: The interdependence of reading and learning. In E.H. Hiebert (Ed.). Reading more: Reading better: Are American students reading enough of the right stuff? (pp. 163-189). New York: Guilford.

Baumann, J. F., Kame'enui, E. J., \& Ash, G. E. (2003). Research on vocabulary instruction: Voltair redux. In J.Flood, D. Lapp, J.R. Squire, \& J.M. Jensen (Eds). Handbook on research on teaching the English language arts. $\left(2^{\text {nd }}\right.$ ed., pp.752-785). Mahwah, $\mathrm{NJ}$ :Erlbaum.

Beck, I., \& McKeown, M. (1991). Conditions of vocabulary acquisition. In R. Barr, M.L. Kamil, P Mosenthal, \& P.D. Pearson. (Eds.). Handbook of reading research, Vol. 2 (pp. 789-814). Mahwah, NJ: Lawrence Erlbaum Associates, Inc.

Beck, I. L., McKeown, M. G., \& Kucan, L. (2002). Bringing words to life: Robust vocabulary instruction. New York, NY: Guilford.

Biemiller, A. (2003). Vocabulary: Needed if more children are to read well. Reading Psychology, 24(3), 323-335.

Blachowicz, C. L. Z., \& Fisher, P. (2000). Vocabulary instruction. In M.L. Kamil, P.B. Mosenthal, P.D. Pearson, \& R. Barr. (Eds.). Handbook of reading research, Vol. 3 (pp. 503 - 523). Mahwah, NJ: Lawrence Erlbaum Associates, Inc..

Blachowicz, C. L. Z., \& Fisher, P. (2004). Vocabulary lessons. Educational Leadership, 61(6), 66-69.

Blachowicz, C. L. Z., Fisher, P., Ogle, D., \& Watts-Taffe, S. (2006). Vocabulary: Questions for the classroom. Reading Research Quarterly, 41, 524-539.

Calfee, R., \& Drum, P. (1978). Learning to read: Theory, research, and practice. Curriculum Inquiry, 8, $183-294$.

Carnevale, L. (2010). Hot words for the SAT ( $4^{\text {th }}$ ed.). Hauppauge, NY: Barron's Educational Series, Inc.

Corbin, J., \& Strauss, A. (2008). Basics of qualitative research ( $3^{\text {rd }}$ ed.). Thousand Oaks, CA: Sage Publications.

Green, S. W., \& Wolf, I. K. (2010). Barron's SAT (24 ${ }^{\text {th }}$ ed.). Hauppauge, NY: Barron's Educational Series, Inc.

Gunning, T. G. (2006). Assessing and correcting reading and writing difficulties ( ${ }^{\text {rd }}$ ed.). Boston, MA: Pearson Education, Inc.

Hardwick-Ivey, A. (2008). Vocabulary in action: Strategies for turning students into Wordsmiths. English Journal, 97(4), 56-61.

Karlsen, B., \& Gardner, E.F. (1996). Stanford Diagnostic Reading Test (4 ${ }^{\text {th }}$ ed.). San Antonio, TX: Harcourt Brace. 
Lesaux, N., Kieffer, M., Faller, S., \& Kelley, J. (2010). The effectiveness and ease of implementation of an academic vocabulary intervention for linguistically diverse students in urban middle-schools. Reading Research Quarterly, 45(2), 196-228.

Marzano, R. J., \& Pickering, D. J. (2005). Building academic vocabulary: Teachers' manual. Alexandria, VA: Association for Supervision and Curriculum.

Nagy, W. W., \& Scott, J. A. (2004). Vocabulary processes. In R.B. Ruddell, \& N.J. Unrau. (Eds.). Theoretical models and processes of reading ( $5^{\text {th }}$ ed.) (pp 574-593). Newark, DE: International Reading Association.

Nagy, W., \& Townsend, D. (2012). Words as tools: Learning academic vocabulary as language acquisition. Reading Research Quarterly, 47(1), 91-108. http://dx.doi.org/10.1002/RRQ.011

National Center for Education Statistics. (2011). The Nation's Report Card: Vocabulary Results from the 2009 and 2011 NAEP Reading Assessments (NCES 2013 452). Institute of Education Sciences, U.S. Department of Education, Washington, D.C.

National Governors Association for Best Practices; Council of Chief State School Officers. (2010). Common Core state standards, literacy. Washington, D.C. Author.

National Institute of Child Health and Human Development (NICHD). (2000). Report of the National Reading Panel. Teaching children to read. (Tech.Rep.No.Publication No. 00-4769). Washington, D.C.: U.S. Government Printing Office.

Reed, D. A. (2004). Vocabulary plus for the new SAT: Vocabulary, reading, and writing exercises for high scores (Books 1-4). Cheswold, DE: Prestwick House, Inc.

Shostak, J. (2005). Vocabulary workshop levels $C$-F. New York, NY: William H. Sadlier-Oxford.

Terrill, C., Scruggs, T., \& Mastropieri. (2004). SAT vocabulary instruction for high school students with learning disabilities. Intervention in School and Clinic, 39, 228-294.

Townsend, D. (2009). Building academic vocabulary in after-school settings: Games for growth with middle school English-language learners. Journal of Adolescent \& Adult Literacy, 53, 242-251. http://dx.doi.org/10.1598/JAAL

\section{(c) $)$ EY}

This work is licensed under a Creative Commons Attribution 3.0 License. 